\title{
Basal and $\beta$-Adrenergic Cardiomyocytes Contractility Dysfunction Induced by Dietary Protein Restriction is Associated with Downregulation of SERCA2a Expression and Disturbance of Endoplasmic Reticulum $\mathrm{Ca}^{2+}$ Regulation in Rats
}

\author{
Arlete R. Penitente ${ }^{a, b, c}$ Rômulo D. Novaes ${ }^{b, c, d}$ Marcelo E. Silva ${ }^{c}$ Márcia F. Silva ${ }^{b, g}$ \\ Judson F. Quintão-Júnior ${ }^{b, g}$ Silvia Guatimosime Jader S. Cruz ${ }^{f}$ \\ Deoclécio A. Chianca-Jrc Antônio J. Natalig Clóvis A. Neves ${ }^{b}$
}

\begin{abstract}
aDepartment of Basic Sciences, Federal University of Jequitinhonha and Mucuri Vale, Diamantina, MG, 'Department of General Biology, Federal University of Viçosa, Viçosa, MG, 'Department of Biological Sciences, Federal University of Ouro Preto, Ouro Preto, MG, 'Department of Cell, Tissue and Developmental Biology, Federal University of Alfenas, Alfenas, MG, eDepartment of Physiology and Biophysics, Federal University of Minas Gerais, Minas Gerais, MG, 'Department of Biochemistry and Immunology, Federal University of Minas Gerais, Minas Gerais, MG, ${ }^{D}$ Department of Physical Education, Federal University of Viçosa, Viçosa MG, Brazil
\end{abstract}

\section{Key Words}

Intracellular calcium - Cardiovascular pathology - Isolated cardiomyocytes - Malnutrition, morphology

\footnotetext{
Abstract

Background: The mechanisms responsible for the cardiac dysfunction associated with dietary protein restriction (PR) are poorly understood. Thus, this study was designed to evaluate the effects of PR on calcium kinetics, basal and $\beta$-adrenergic contractility in murine ventricular cardiomyocytes. Methods: After breastfeeding male Fisher rats were distributed into a control group $(C G, n=20)$ and a protein-restricted group (PRG, $n=20$ ), receiving isocaloric diets for 35 days containing $15 \%$ and $6 \%$ protein, respectively. Biometric and hemodynamic variables were measured. After euthanasia left ventricles (LV) were collected for histopathological evaluation, SERCA2a expression, cardiomyocytes contractility and $\mathrm{Ca}^{2+}$ sparks analysis. Results: PRG animals showed reduced general growth, increased heart rate and arterial pressure. These animals presented extracellular matrix expansion and disorganization, cardiomyocytes hypotrophy, reduced amplitudes of shortening and maximum velocity of contraction and relaxation at baseline and after $\beta$-adrenergic stimulation. Reduced SERCA2a 
expression as well as higher frequency and lower amplitude of $\mathrm{Ca}^{2+}$ sparks were observed in PRG cardiomyocytes. Conclusion: The observations reveal that protein restriction induces marked myocardial morphofunctional damage. The pathological changes of cardiomyocyte mechanics suggest the potential involvement of the $\beta$-adrenergic system, which is possibly associated with changes in SERCA2a expression and disturbances in $\mathrm{Ca}^{2+}$ intracellular kinetics.

Copyright (C) 2014 S. Karger AG, Basel

\section{Introduction}

There is evidence that malnutrition in early life stages is associated with cardiac dysfunction $[1,2]$. Despite the extensive literature on the impact of malnutrition in the digestive, endocrine, and musculoskeletal systems [3, 4], little is known about how different dietary regimens act to modulate the function of the cardiovascular system [5, 6]. Even more scarce is information regarding the cardiac molecular and cellular adaptations that are induced by protein restriction, which can potentially modify the biomechanical contractile pattern of cardiomyocytes [5]. Previous studies indicated that a 50\% food restriction is able to induce cardiac dysfunction that manifests as pathological changes in contraction and relaxation of the whole heart [7], which are possibly associated with a decreased sensitivity to calcium [8]. However, the current evidence does not allow determining how much each of the individual diet components contributed to or was a determinant of cardiac dysfunction. Moreover, the mechanical behavior of isolated cardiomyocytes under conditions of low protein remained an issue that is still not well resolved.

Recently, our research group described for the first time that protein restriction induces a marked morphofuctional reorganization of the myocardium that coexists with cardiomyocytes biomechanical dysfunction in rats. In this study, the initial evidences indicate that contractile insufficiency was probably associated with pathological changes of the intracellular calcium kinetics, rather than inadequate available amounts of this mineral in cardiac tissue [9].

The scarcity of studies on the cellular effects of malnutrition in cardiac tissue indicates that this area of investigation remains neglected, making it difficult to understand the pathogenic mechanisms associated with heart failure in this condition. Thus, further studies are needed to elucidate the physiological and molecular pathways involved in cell biomechanics dysfunction, as well as the integrity of mechanisms associated with cardiomyocytes contractile adaptation in response to pharmacological stimuli in a condition of low protein intake. Considering that the understanding of the influence of malnutrition on heart dysfunction is essential for the design of rational intervention strategies, the present study was designed to investigate the basal $\mathrm{Ca}^{2+}$ control from smooth endoplasmic reticulum, the expression of SERCA2a and the involvement of the $\beta$-adrenergic system in cardiomyocyte mechanical dysfunction induced by severe protein restriction in rats.

\section{Material and Methods}

\section{Animals}

Twenty-eight day old male Fischer rats provided by the animal facilities of the Federal Unversity of Ouro Preto (UFOP), Brazil, were distributed according to the diet received: a control group (CG, $n$ $=20$ ), normal protein diets and protein-restricted group (PRG, $\mathrm{n}=20$ ). After weaning, $\mathrm{CG}$ animals were fed with standard rodent chow (AIN-93 - 15\% protein) and the PRG animals were submitted to severe protein restriction receiving a diet containing 6\% protein (casein) (17). The diets were administered for 35 days, were isocaloric ( $422 \mathrm{kcal} / 100 \mathrm{~g}$ of diet) and the salts and vitamins were at similar concentrations in both diets (Penitente et al., 2007) (Table 1). The animals were maintained in a room with a controlled temperature $\left(22 \pm 2^{\circ} \mathrm{C}\right)$ and humidity (60-70\%) with 12-hour light/dark cycles and water ad libitum. The experimental protocols were approved by the institutional ethics committee (UFV protocol 95/2011). 
Penitente et al.: Protein Restriction and Cardiomyocytes Dysfunction

Table 1. Chemical composition of the diets (g/1000g of chow). CG (control group), 15\% protein (casein); PRG (protein-restricted group), $6 \%$ protein (casein)

\begin{tabular}{lcc}
\hline \multicolumn{1}{c}{ Diet ingredients } & CG & PRG \\
\hline Protein (casein) & 150 & 60 \\
Corn starch & 680 & 770 \\
Soybean oil & 100 & 100 \\
Salts mix & 50 & 50 \\
Vitamin mix & 10 & 10 \\
Fiber (cellulose) & 10 & 10 \\
Total caloric values & $4220 \mathrm{Kcal}$ & $4220 \mathrm{Kcal}$ \\
\hline
\end{tabular}

In vivo hemodynamic analysis

One day prior to the cardiovascular recordings, animals received polyethylene catheters into the femoral artery (for cardiovascular measurements) under tribromoethanol (2.5\%, Merck, Darm-stadt, Germany) anesthesia. The catheters were tunneled through the subcutaneous and exteriorized on the back of the neck. The animals were maintained in individual cages in the experimental room until the next day to recover from anesthesia and adapt to the experimental room [5].

On the experimental day, the arterial catheter was connected to a pressure transducer MLT0699 (ADInstruments, Bella Vista, New South Wales, Australia) and connected to a signal amplifier ETH-400 (CB Sciences Inc., USA). The pulsatile arterial pressure was recorded through a digital acquisition system (PowerLab/400, ADInstruments, Bella Vista, New South Wales, Australia). Mean arterial pressure and heart rate were derived on-line from the pulsatile arterial pressure using Chart4 software (ADInstruments, Bella Vista, New South Wales, Australia) [5].

\section{Biochemical analysis and heart biometry}

Thirty-five days after dietary protein restriction the animals from each group were weighed and euthanized under anesthesia. Blood samples were collected by cardiac puncture and centrifuged. Biochemical measurements were performed for serum albumin, globulin, glucose, hemoglobin, hematocrit and total protein by enzymatic colorimetric methods using commercial diagnostic kits (Human in Vitro Diagnostics, Minas Gerais, Brazil) [10].

For biometrical analyses, the hearts from 10 animals of each group were arrested in diastole with a 1 -ml injection of a $1 \mathrm{M}$ potassium chloride into the right atrium. The left ventricles (LV) were dissected and weighed separately [9]. The relative heart and LV weight was calculated by dividing the heart mass and LV mass by the tibia length (TL).

\section{Cardiomyocytes preparation}

After euthanasia, the hearts from other 10 animals were quickly removed and LV cardiomyocytes were isolated as described by Novaes et al. [11]. Briefly, each heart was cannulated through the aorta in a Langendorff system and perfused with isolation solution (composition $[\mathrm{mM}]: 130 \mathrm{Na}^{+}, 5.4 \mathrm{~K}^{+}, 1.4 \mathrm{Mg}^{2+}, 140$ $\mathrm{Cl} ; 0.75 \mathrm{Ca}^{2+}, 5$ Hepes, 10 glucose, 20 taurine and 10 creatine, $\mathrm{pH}=7.3$ at room temperature). Each heart was then perfused with a calcium-free solution containing $0.1 \mathrm{mM}$ ethylene glycol-bis (beta-aminoethyl ether)- $N$, $N, N^{\prime}, N^{\prime}$-tetra-acetic acid (EGTA) for $5 \mathrm{~min}$. The hearts were then perfused with a solution containing $1.0 \mathrm{mg}$. $\mathrm{ml}^{-1}$ of type 2 collagenase (Worthington, USA) and $100 \mathrm{mM} \mathrm{CaCl} 2$ for $25 \mathrm{~min}$. The solutions were oxygenated $\left(100 \%\right.$ 02, White Martins, SP, Brazil) and maintained at $35^{\circ} \mathrm{C}$. After perfusion, the left ventricle was dissected and placed in a glass receptacle with an enzyme solution containing collagenase $(5 \mathrm{ml})$ and bovine serum albumin $(10 \%)$. The receptacle was shaken moderately for $5 \mathrm{~min}$ at $37^{\circ} \mathrm{C}$, after which the solution was centrifuged. The supernatant was removed and the cardiomyocytes were resuspended in an isolation solution, stored in a refrigerator $\left(5^{\circ} \mathrm{C}\right)$ and used up to $4 \mathrm{~h}$ after isolation. Only calcium-tolerant, quiescent, rod-shaped cardiomyocytes showing clear cross striations were studied.

\section{Cardiomyocytes biomechanical analysis}

Cardiomyocyte contractile function was measured using an edge motion detection system (Ionoptix, Milton, MA, USA) mounted on an inverted microscope (Nikon Eclipse TS100 ${ }^{\circledR}$, Tokyo, Japan), as previously described [11]. Briefly, myocytes were placed in an experimental chamber with the base glass and bathed 
Penitente et al.: Protein Restriction and Cardiomyocytes Dysfunction

in buffer with the following composition (in $\mathrm{mM}$ ): $136.9 \mathrm{NaCl}$; $5.4 \mathrm{KCl}$; $0.37 \mathrm{NaH} 2 \mathrm{PO} 4 ; 0.57 \mathrm{MgCl} 2 ; 5$ Hepes; 5.6 glucose; and $1.8 \mathrm{CaCl} 2$ ( $\mathrm{pH}=7.4$ at room temperature). Cardiomyocytes were field stimulated at a frequency of $3 \mathrm{~Hz}$ (10 volts, 5 min duration) using a pair of steel electrodes (Myopacer, Ionoptix, MA, USA). Cardiomyocytes were visualized on a personal computer monitor with an NTSC camera (MyoCam, Ionoptix, MA, USA) attached to the microscope using an image detection program (Ionwizard, Ionoptix, MA, USA). This image was used to measure cell shortening (our index of contractility) in response to electrical stimulation using a video motion edge detector (IonWizard; IonOptix, MA, USA). All parameters were evaluated using customized software developed using the MatLab ${ }^{\circledR}$ platform. Cell shortening from stimulation time (expressed as a percentage of resting cell length) to the peak of shortening and time to half relaxation were measured and calculated as previously described.

\section{$\beta$-adrenergic contractile stimulation}

The contractile response of cardiomyocytes to $\beta$-adrenergic stimulation was assessed using the nonselective agonist isoproterenol (ISO, 1, 2 and $3 \mathrm{mM}$ ) at a stimulation rate of $1 \mathrm{~Hz}$. After recording the baseline cell shortening, ISO was infused in the experimental chamber through an automatic pipette. The cells were electrically stimulated after 5 min of infusion when cell shortening was recorded [11]. This procedure was repeated for each ISO concentration in different myocytes.

\section{$\mathrm{Ca}^{2+}$ sparks analysis}

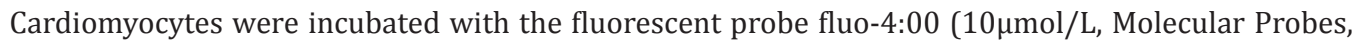
Eugene, OR, USA) at room temperature for 20 minutes. The cells were washed with Tyrode's solution to remove the excess probe [12]. $\mathrm{Ca}^{2+}$ sparks were analyzed using a confocal microscope (LSM 510 Meta Zeiss, Jena, Germany) with a $63 \times$ oil immersion objective lens and an argon laser at $488 \mathrm{~nm}$. The cell images were digitized at 512 pixels and the axis of the cell scan was positioned lengthwise, being careful not to intercept regions of nuclei. Cardiomyocytes were scanned at $1.54 \mathrm{~ms}$ and the sequence of scans was obtained in a series to create two-dimensional images. Digital image processing was performed using custom routines written in IDL (Research Systems, Boulder, CO, USA). The $\mathrm{Ca}^{2+}$ sparks amplitudes are represented as $\Delta \mathrm{F} / \mathrm{F} 0$, where $\Delta \mathrm{F}$ is the variation in fluorescence intensity compared to the minimal fluorescence (F0) measured at each $\mathrm{Ca}^{2+}$ sparks.

\section{Analysis of SERCA2a expression}

After isolation, left ventricular cardiomyocytes from 5 animals per group were homogenized in lysis buffer $(100 \mathrm{mM} \mathrm{NaCl}, 50 \mathrm{mM}$ Tris-base, 5mM EDTA-2Na, 50mM Na4P207.10H2O, $1 \mathrm{mM} \mathrm{MgCl} 2,1 \%$ Nonidet $\mathrm{P} 40,0.3 \%$ Triton $\mathrm{x}-100$, and $0.5 \%$ sodium deoxycholate; $\mathrm{pH}=8)$, containing protease inhibitors $(200 \mathrm{mM}$ PMSF, $15.7 \mathrm{mg} / \mathrm{mL}$ benzamidine, and $10 \mu \mathrm{M}$ pepstatin) and phosphatase inhibitors $(20 \mathrm{mM} \mathrm{NaF}$, and $1 \mathrm{mM}$ $\mathrm{Na} 3 \mathrm{VO} 4)$ and then centrifuged at $8000 \mathrm{~g}\left(4^{\circ} \mathrm{C}\right)$.

Total proteins were quantified using the Bradford method. 30mg of protein was diluted in buffer (5X$2 \mathrm{M}$ Tris, $\mathrm{pH}=6.8 ; 20 \%$ Glycerol, 30\% SDS, 25\% mercaptoethanol, 0.1\% Bromophenol Blue) for separation by SDS-PAGE using a standard molecular weight (BIO-RAD). After separation in the gel, proteins were transferred to a PVDF membrane (Millipore, Billerica, MA, USA) with a pore size of $0.45 \mu \mathrm{m}$. The quality of the transfer was monitored by staining the membrane with solution of Ponceau $(0.2 \%)$. The membranes were washed with TBS-Tween $(0.05 \%$ Tween) and placed in blocking solution for 1 hour. They were then incubated at $4^{\circ} \mathrm{C}$ with primary specific antibodies: anti-glyceraldehyde 3-phosphate dehydrogenase (GAPDH) [1:6000], (Santa Cruz Biotechnology, Santa Cruz, CA, USA), anti-SERCA2a [1:1000], washed with TBS containing $0.2 \%$ Tween20 (TBST) for 5 minutes (three times) and then incubated for 2 hours with secondary antibody conjugated to peroxidase (HRP) (1:5000, anti-goat IgG-HRP and anti-rabbit IgG-HRP (Sigma, St. Louis, MO, USA). The protein bands were detected by a chemiluminescence reaction (kit ECL plus, Amersham Biosciences Limited, Little Chalfont, Buckinghamshire, England, UK). The intensity of bands was evaluated by densitometric analysis using the ImageQuant ${ }^{\mathrm{TM}}$ software (Amersham Biosciences Limited). Protein levels were normalized by the GAPDH expression level [13].

\section{Analysis of cell death by DNA fragmentation assay}

DNA extraction and purification was performed according Coombs et al., [14]. Briefly, fragments of the cardiac tissue $(20 \mathrm{mg})$ were incubated with proteinase $\mathrm{K}(10 \mathrm{mg} / \mathrm{mL})$ at $55^{\circ} \mathrm{C}$. DNA was extracted the by the 
Penitente et al.: Protein Restriction and Cardiomyocytes Dysfunction

Table 2. Effect of dietary protein restriction on serum biochemical parameters. CG, control group (15\% protein); PRG, protein-restricted group (6\% protein); Data are expressed as mean \pm SEM. *Denotes statistical difference compared to CG $(\mathrm{p}<0.01)$

\begin{tabular}{lcc}
\hline Biochemical variables & CG & PRG \\
\hline Albumin (g/dL) & $4.00 \pm 0.47$ & $2.20 \pm 0.04^{*}$ \\
Globulin (g/dL) & $3.10 \pm 0.15$ & $2.80 \pm 0.06^{*}$ \\
Glucose (mg/dL) & $126.70 \pm 10.10$ & $95.0 \pm 7.10^{*}$ \\
Haemoglobin (mg/dL) & $15.60 \pm 0.50$ & $12.10 \pm 0.35^{*}$ \\
Hematocrit $(\%)$ & $43.10 \pm 1.04$ & $35.20 \pm 2.10^{*}$ \\
Total protein $(\mathrm{g} / \mathrm{dL})$ & $7.10 \pm 0.04$ & $6.00 \pm 0.09^{*}$ \\
\hline
\end{tabular}

phenol-chloroform (1:1) method. Nucleic acid fragmentation was investigated using DNA electrophoresis in a $2 \%$ agarose gel containing ethidium bromide visualized on a UV transilluminator.

Light and Scanning electron microscopy

LV samples from the same 10 animals used for heart biometry were fixed for 48 hours in histological fixative (freshly prepared $10 \% \mathrm{w} / \mathrm{v}$ formaldehyde in $0.1 \mathrm{M}$ phosphate buffer $\mathrm{pH} 7.2$ ) and used for histopathological analysis. For light microscopy LV fragments were dehydrated in ethanol, cleared in xylol and embedded in paraffin. Blocks were cut into 4- $\mu$ m sections, stained by hematoxylin-eosin (H\&E) and mounted on histology slides. The slides were visualized and the images captured using a light microscope (Olympus BX-60 ${ }^{\circledR}$, Tokyo, Japan) connected to a digital camera (Olympus QColor- $3^{\circledR}$, Tokyo, Japan). Sixty fields from H\&E (objective $\times 40$ ) were randomly chosen and a total of $4.37 \times 10^{6} \mu \mathrm{m}^{2}$ myocardium area was analyzed [11]. Histopathological parameters of cardiomyocytes hypotrophy, inflammatory infiltrate, pyknosis, cardiomyocytes and extracellular matrix distribution and organization were observed.

For scanning electron microscopy adjacent LV fragments of the same animals were submitted to $\mathrm{NaOH}$ maceration method for isolation the extracellular matrix [15]. The samples were immersed in a $10 \% \mathrm{NaOH}$ solution for 6 days at room temperature and then rinsed in distilled water until they became transparent. They were immersed in 1\% tannic acid for 4 hours, rinsed in distilled water overnight, and post-fixed in 1\% osmium tetroxide for 2 hours, dehydrated in ethanol, submitted to critical point drying (CPD 030, Bal-tec, Witten, North Rhine-Westphalia, Germany), coated with gold, and observed under a Leo 1430VP scanning electron microscope (Carl Zeiss, Jena, Thuringia, Germany). Extracellular matrix distribution and organization were used as histopathological indicators.

\section{Statistical analysis}

Data were expressed as mean and the standard error of the mean (mean \pm SEM). The normal distribution of data was verified using the Kolmogorov-Smirnov test. Biometric and cell contractile function data were compared using the Student's t test. A p value $<0.05$ was considered statistically significant.

\section{Results}

Serum biochemistry and biometry

As shown in Table 2, the level of protein restriction applied here was sufficient to induce marked biochemical changes in serum. PRG animals presented significant reduction $(p<0.01)$ in all parameters investigated, especially in serum protein content.

The biometric parameters of both groups investigated are shown in Table 3. In the PRG, there was a significant decrease in the body, heart and LV masses compared to the CG $(\mathrm{p}<0.001)$. In addition, animals in the PRG represented a significant increase in the relationship of heart mass/tibia length and LV mass/tibia length compared to the CG $(\mathrm{p}<0.001)$. 
Table 3. Effect of dietary protein restriction on biometric parameters. CG, control group (15\% protein); PRG, protein-restricted group (6\% protein); VE, left ventricle; TL, tibia length. Data are expressed as mean \pm SEM. *Denotes statistical difference compared to CG $(\mathrm{p}<0.001)$

\begin{tabular}{lcc}
\hline \multicolumn{1}{c}{ Parameters } & CG & PRG \\
\hline Initial body mass $(\mathrm{g})$ & $70.00 \pm 1.31$ & $71.00 \pm 1.20$ \\
Final body mass $(\mathrm{g})$ & $228.00 \pm 3.31$ & $70.00 \pm 1.38^{*}$ \\
Heart mass $(\mathrm{g})$ & $1.06 \pm 0.03$ & $0.45 \pm 0.01^{*}$ \\
LV Mass $(\mathrm{g})$ & $0.98 \pm 0.03$ & $0.42 \pm 0.01^{*}$ \\
Heart mass / TL $(\mathrm{mg} / \mathrm{cm})$ & $0.31 \pm 0.05$ & $0.16 \pm 0.02^{*}$ \\
LV Mass $/ \mathrm{TL}(\mathrm{mg} / \mathrm{cm})$ & $0.28 \pm 0.06$ & $0.15 \pm 0.02 *$ \\
\hline
\end{tabular}

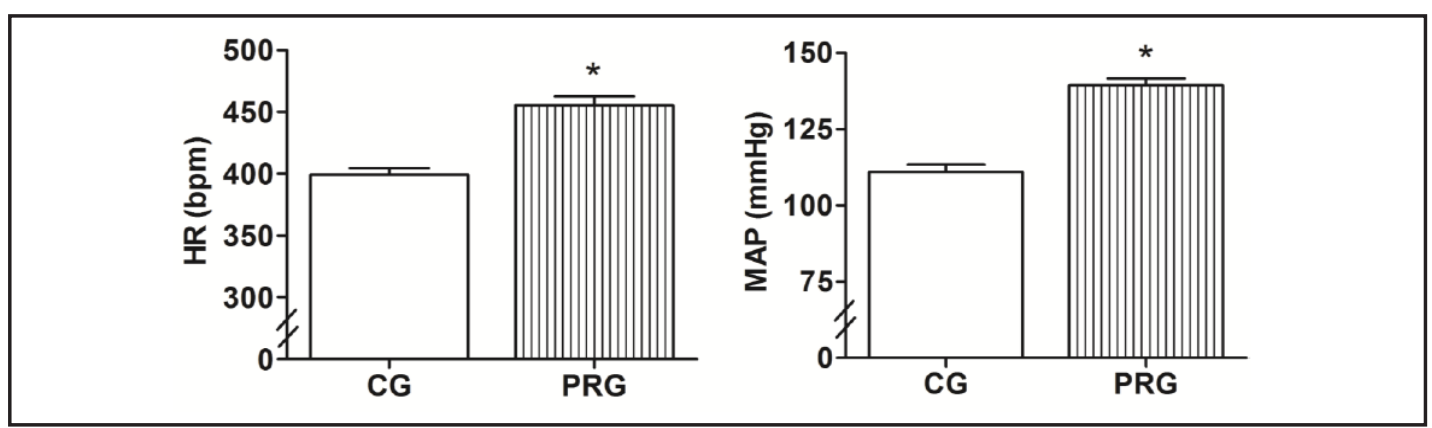

Fig. 1. Effect of dietary protein restriction on heart rate (HR) and mean arterial pressure (MAP) in Fisher rats. CG, control group (15\% protein); PRG, protein-restricted group (6\% protein). bpm, beat per minute; MAP, mean arterial pressure. Data expressed as mean \pm SEM. *Denotes statistical difference compared to CG $(\mathrm{p}<0.001)$.

\section{Hemodynamic}

The hemodynamic parameters of both groups investigated are shown in Figure 1. Dietary protein restriction was able to induce a significant increase in heart rate and mean arterial pressure in PRG compared to CG (Fig. 1).

\section{Cardiomyocytes contractility}

Figure 2 shows the basal cellular contractile parameters in both of the groups investigated. The animals in the PRG showed a significant reduction in cardiomyocyte contraction amplitudes, and the maximal velocity of contraction and relaxation compared to the $C G(p<0.001)$.

\section{Contractile response to $\beta$-adrenergic stimulation}

Figure 3 shows the response of cardiomyocytes to $\beta$-adrenergic stimulation. Cardiomyocytes from PRG animals showed a marked attenuation of contractile response at all concentrations of ISO $(1,2$ and $3 \mathrm{mM})$ compared to the CG. In a condition of protein restriction, cardiomyocytes showed a significant reduction in contraction amplitude and a prolongation of relaxation compared to CG animals $(\mathrm{p}<0.001)$.

\section{$\mathrm{Ca}^{2+}$ Sparks}

The results of spontaneous $\mathrm{Ca}^{2+}$ sparks in quiescent cardiomyocytes during diastole are shown in Figure 4. The $\mathrm{Ca}^{2+}$ sparks amplitude was significantly lower $(\mathrm{p}<0.001)$ in the PRG compared to the CG $\left(0.26 \pm 0.001\right.$ vs. $0.32 \pm 0.001 \mathrm{~ms}$, respectively). On the contrary, the $\mathrm{Ca}^{2+}$ sparks frequency was significantly higher $(\mathrm{p}<0.001)$ in the PRG compared to the CG $(9.54 \pm$ 0.25 vs. $7.82 \pm 0.35$ sparks $\times 100 \mathrm{~m}^{-1} \mathrm{X} \mathrm{s}^{-1}$, respectively). 

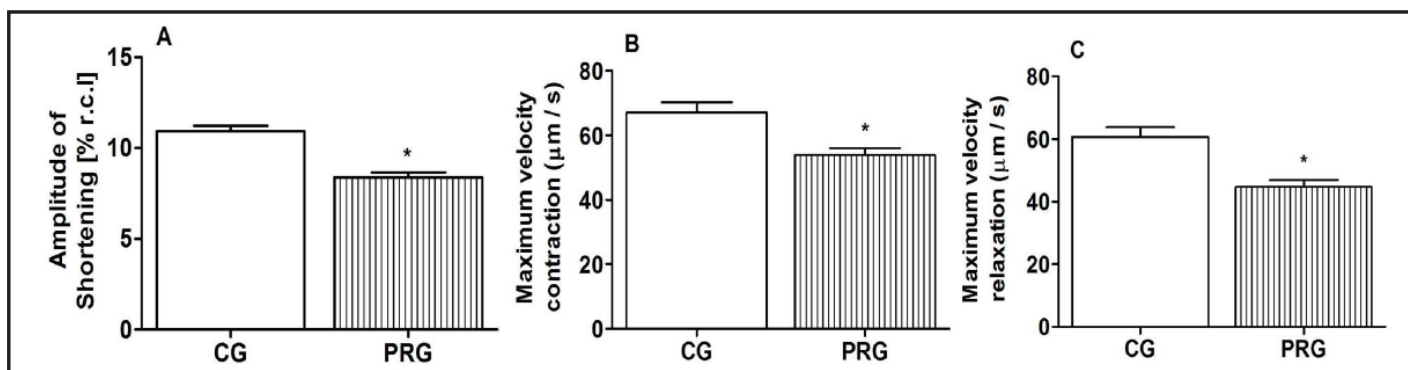

Fig. 2. Effect of dietary protein restriction on contractile function of left ventricular cardiomyocytes from Fisher rats. CG, control group (15\% protein); PRG, protein-restricted group ( $6 \%$ protein). Amplitude of shortening is expressed as a \% of resting cell length (\% r.c.l.). Data expressed as mean \pm SEM. *Denotes statistical difference compared to CG $(\mathrm{p}<0.001)$.

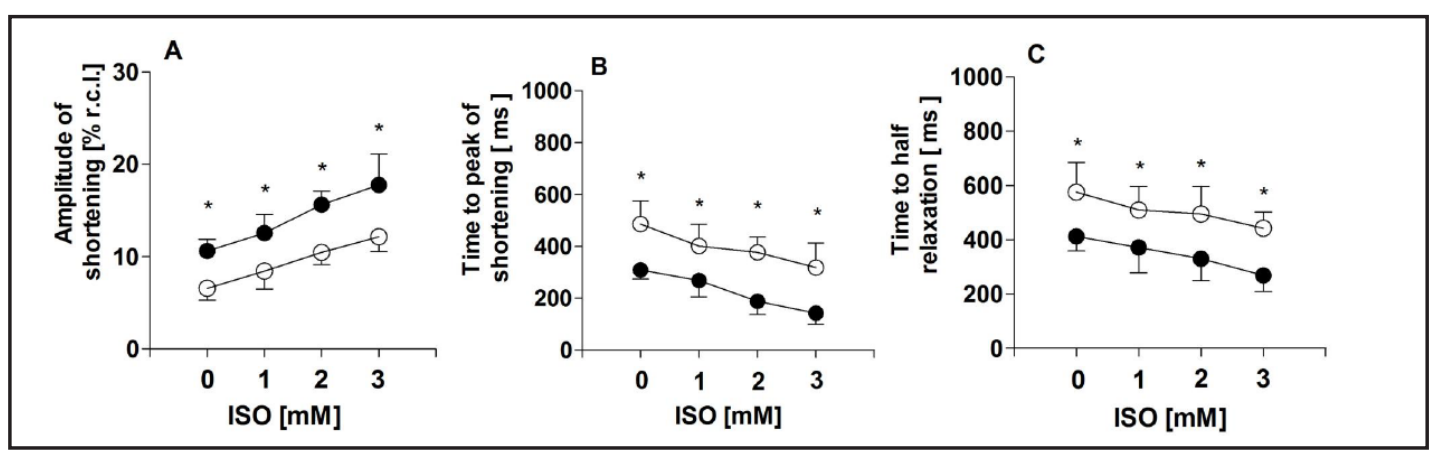

Fig. 3. Effect of dietary protein restriction on dose-dependent contractile pattern to $\beta$-adrenergic stimulation in left ventricular cardiomyocytes from Fisher rats. CG, control group (15\% protein, closed circle); PRG, protein-restricted group (6\% protein, open circle). Amplitude of shortening is expressed as a \% of resting cell length (\% r.c.l.). Data expressed as mean \pm SEM. *Denotes statistical difference compared to CG $(\mathrm{p}<0.001)$.
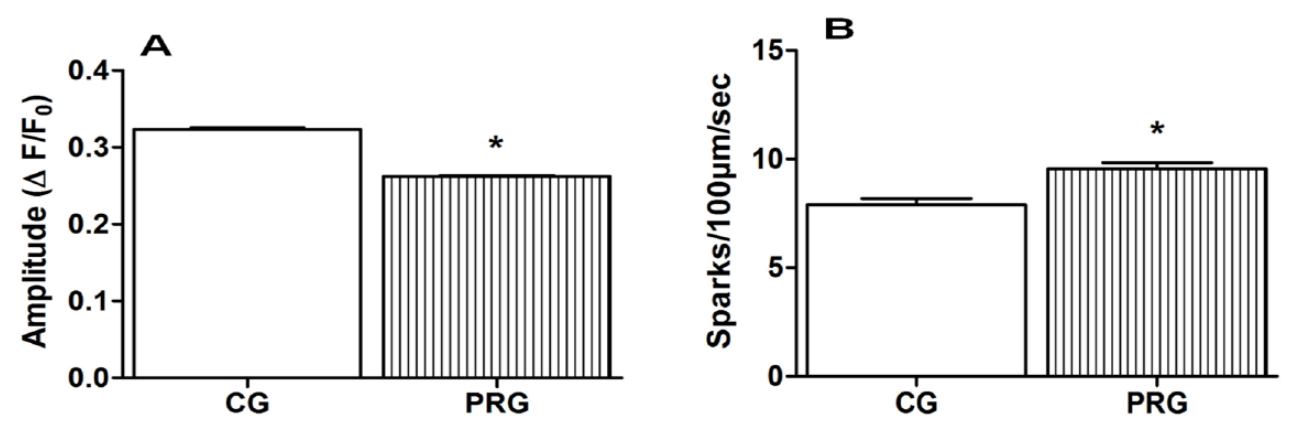

Fig. 4. Effect of protein dietary restriction on spontaneous pulses of calcium ( $\mathrm{Ca}^{2+}$ Sparks) from smooth endoplasmic reticulum in left ventricular cardiomyocytes from Fisher rats. CG, control group (15\% protein); $P R G$, protein-restricted group ( $6 \%$ protein). $\Delta \mathrm{F}$, variation in fluorescence intensity compared to the minimal fluorescence (F0). Data expressed as mean \pm SEM. ${ }^{*}$ Denotes statistical difference compared to CG $(\mathrm{p}<0.001)$.

\section{SERCA2a expression}

The measurement of SERCA2a expression is represented in Figure 5. The rats submitted to dietary protein restriction showed a significant reduction in SERCA2a expression compared to GC $(\mathrm{p}<0.001)$. 
Fig. 5. Western blot analysis of sarcoplasmic reticulum $\mathrm{Ca}^{2+}$-ATPase (SERCA2a) and glyceraldehyde 3-phosphate dehydrogenase (GAP$\mathrm{DH}$ ) protein expression in left ventricular cardiomyocytes from Fisher rats. CG, control group (15\% protein; $\mathrm{n}=5$ ); PRG, protein-restricted group $(6 \%$ protein; $n=$ $5)$. Data expressed as mean \pm SEM. *Denotes statistical difference compared to CG $(\mathrm{p}<0.001)$.

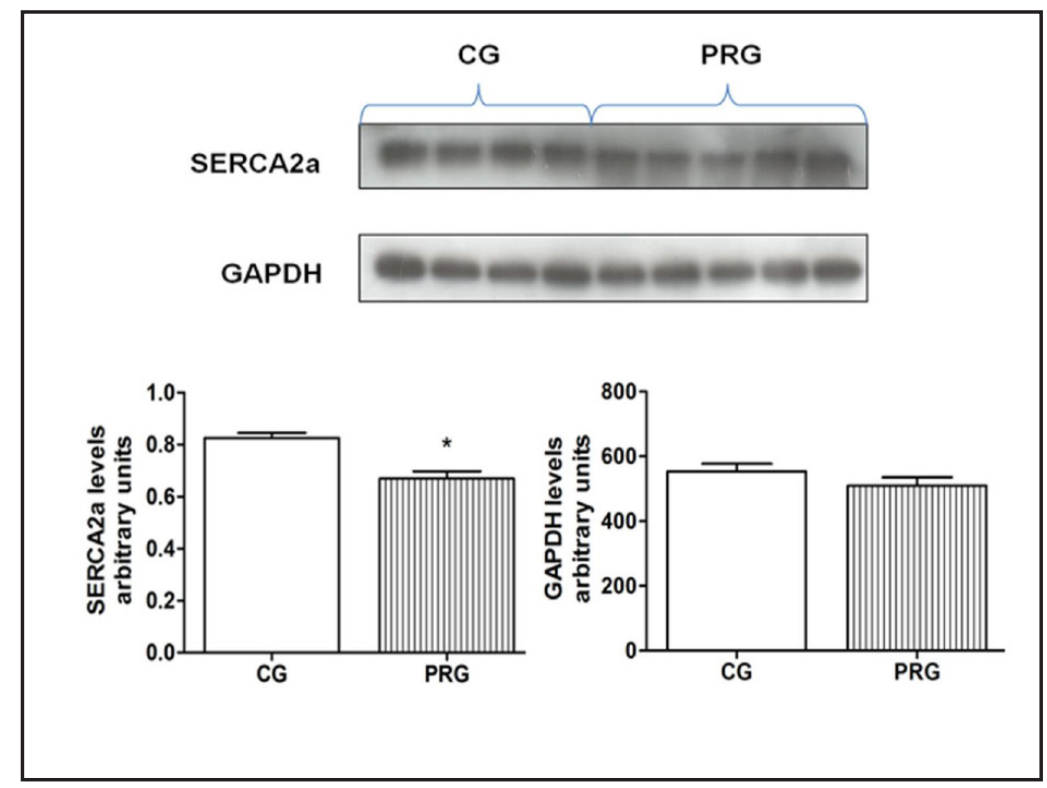

Fig. 6. DNA fragmentation assay of the cardiac tissue from Fisher rats treated with a normal or low protein diet. CG, control group (15\% protein); PRG, protein-restricted group ( $6 \%$ protein). The electrophoretic pattern was similar in both groups.

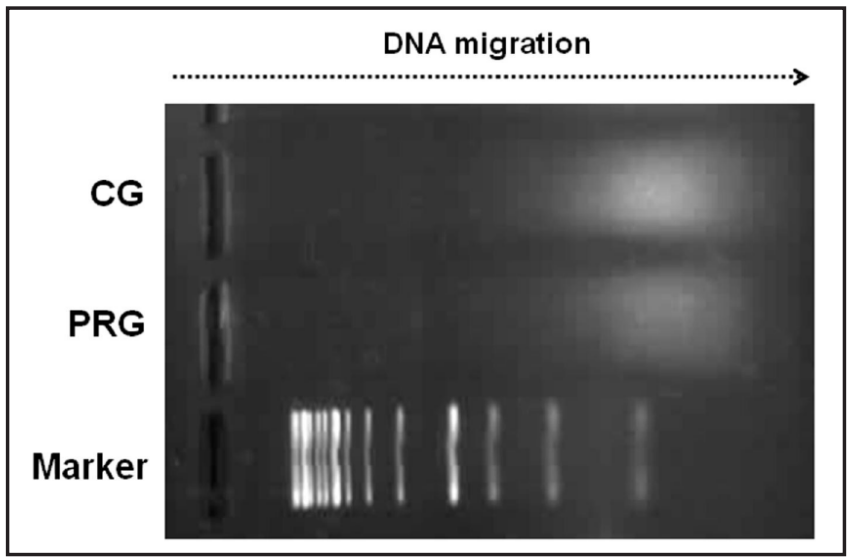

Cell death

The electrophoretic pattern of the genomic DNA extracted from cardiac tissue was similar in both groups, indicating no fragmentation (Fig. 6).

\section{Myocardial histopathology}

Figure 7 shows the microscopic aspect of the LV myocardial tissue in both animal groups. Under light microscopy, PRG presented hypotrophic cardiomyocytes with an irregular distribution surrounding by an expanded extracellular matrix (EM). The images obtained by scanning electron microscopy corroborated the evidence of EM expansion, revealed a disorganized pattern of collagen fibers distribution and reduced spaces occupied by cardiomyocytes in PRG compared to CG.

\section{Discussion}

The results indicated that the protein restriction protocol applied in the present study was effective in induce a systemic condition of malnutrition. This finding was corroborated mainly by marked protein depletion in serum, reduced absolute and relative body mass, and morphological and functional changes in the heart. Although it was evident the reduction in cardiac mass in PRG animals, apparently this change is not related to cell death, indicating that 
Fig. 7. Effect of dietary protein restriction on left ventricle microstructure in Fisher rats. Top panels: ventricular parenchyma of the control group (CG, 15\% protein) presented a well-organized structure compared to the protein-restricted group (PRG, $6 \%$ protein), in which were observed hypotrophic cardiomyocytes and expanded extracellular matrix (H\&E staining under bright field microscopy). Bottom panels: Scanning electron photomicrographs showing disorganized extracellular matrix and reduced spaces occupied by cardiomyocytes (asterisk) in PRG compared to CG ( $\mathrm{NaOH}$ maceration method for extracellular matrix). Cell debris (arrow).

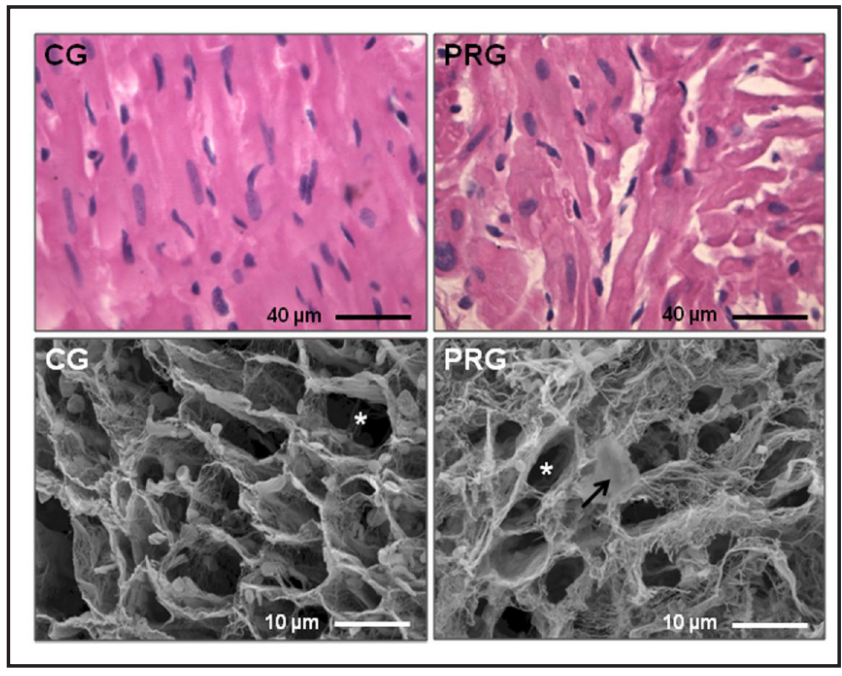

the protein restriction level applied here was not sufficient to compromise cardiomyocytes viability. It has been shown that nutritional deficiency, even if transitory, could modify the organism structure and metabolism in a systemic way, affecting the development and function of multiple organs $[1-3,7,16]$. It is possible that the anatomical changes observed in the hearts of the PRG are adaptations of the body to adjust to adverse nutritional conditions and survive $[2,17]$.

In the present study, apparently the biometric adjustments were not enough to prevent the installation of changes in heart rate and elevated blood pressure in response to protein restriction. There is sufficient evidence that different conditions of malnutrition is associated or represents an important risk factor for cardiovascular abnormalities [2, 3, 6, 16]. However, little is known about the influence of specific dietary components on cardiovascular structure and function. Thus, the hemodynamic findings indicated that proteins are important dietary components involved in the functional development of the cardiovascular system, with an evident participation in the homeostatic adjustments of the heart rate and arterial pressure. Several hypotheses have been suggested to explain the hemodynamic changes associated with malnutrition. Considering the model investigated, appears to be more relevant the hypothesis of reduced amino acids bioavailability, which is associated to structural abnormalities of the parenchyma and stroma in different organs of the cardiovascular system, especially the heart [2,9]. Furthermore, a lower efficiency in the synthesis of peptide regulatory molecules such as neurotransmitters, growth factors and intracellular signaling molecules can also directly associated with reduced amino acids levels [6]. Although the impact of reduced amino acids bioavailability on embryonic cardiovascular development is evident, postnatal malnutrition has also proven to be extremely detrimental to the structural organization and function of the cardiovascular system, increasing morbidity and mortality from diseases of this system $[3,5]$.

The animals of the PRG showed marked contractile dysfunction in basal conditions and after $\beta$-adrenergic stimulation. Although the response to $\beta$-adrenergic stimulation was dose-dependent for both groups, PRG animals presented an attenuation of all contractile parameters that were analyzed. Furthermore, there was a marked reduction in cell contractility in response to stimuli of increasing intensity, suggesting that low protein intake reduce the functional reserve in cardiomyocytes and responsiveness to sympathetic stimulation. Similar results were described by McKnight et al. [18], indicating that a 75\% dietary restriction was able to induce pathological changes in response to $\beta$-adrenergic stimulation in a preparation of isolated papillary muscle. These findings indicate that the myocardial contractile incompetence presents a cellular basis, which goes beyond the morphological changes of the heart parenchyma and stroma induced by protein 
restriction. It has been suggested that malnutrition may alter the adrenergic response due to attenuation of the phosphorylation of proteins related to the control of intracellular $\mathrm{Ca}^{2+}$, impairing the mechanical cardiac performance in murine models $[7,19]$. Moreover, there is evidence that these changes may be associated with a decreased number of $\beta$-adrenergic receptors or alterations of intracellular signal transduction pathways dependent on the adrenergic activation of $G$ protein [8]. However, the modulatory effect of protein restriction on $\beta$-adrenergic receptors expression and/or function still poorly understood, and needs to be established in further studies.

In addition to contractile dysfunction, a reduced expression of the $\mathrm{Ca}^{2+} \mathrm{ATP}$-dependent transporter of the sarcoplasmic reticulum (SERCA2a) was observed in cardiomyocytes from the PRG. This finding is consistent with the potential inhibition of calcium uptake by the sarcoplasmic reticulum during relaxation of cardiomyocytes. The principal component associated with the $\left[\mathrm{Ca}^{2+}\right] \mathrm{i}$ transient control is SERCA2a. This transporter is responsible for the higher rate of re-uptake of cytosolic $\mathrm{Ca}^{2+}(90 \%)$ [20] and its expression, structure and/ or function are often impaired in heart diseases with different aetiologies, such as diabetes mellitus, hypertension, and autoimmune cardiomyopathies [11, 21]. Pathological changes of SERCA2a resulted in a lower re-uptake of cytosolic $\mathrm{Ca}^{2+}$ into the sarcoplasmic reticulum, and an increased cytosolic $\mathrm{Ca}^{2+}$ concentration, impairing cell relaxation $[22,23]$. Thus, it is not unrealistic to assume that the lower activity of SERCA2a induced by low protein applied in the experimental model investigated may be related to attenuation of cardiomyocyte relaxation. This explains, in part, the prolongation of relaxation time observed in the PRG cardiomyocytes, which is possibly related to the elevation of cytosolic $\mathrm{Ca}^{2+}$ that is dependent on the lower reuptake of the cytosolic $\mathrm{Ca}^{2+}$ to the sarcoplasmic reticulum by SERCA2a.

The frequency and amplitude of basal spontaneous pulses of $\mathrm{Ca}^{2+}$ from the sarcoplasmic reticulum $\left(\mathrm{Ca}^{2+}\right.$ sparks $)$ are important indicators of the functional state of the ryanodine channels (RyR2) [20]. A smaller amplitude and higher frequency of $\mathrm{Ca}^{2+}$ sparks was evidenced in the PRG compared to the CG. These results indicate that low protein dietary intake can modify the function of RyR2. Other researchers, working with different animal models of cardiac dysfunction, also found similar results to those found in this study [22, 24].

The abnormal activity of RyR2 has been shown in different types of heart disease [22, $24,25,26]$. A common feature in most models of experimental heart failure is the decline of the $\mathrm{Ca}^{2+}$ content of the sarcoplasmic reticulum. This change can be caused by changes in the function of SERCA2a, the $\mathrm{Na}^{+} / \mathrm{Ca}^{2+}$ transporter of the sarcolemma (NCX) and RyR2 [25]. However, detailed analysis of these molecular transporters requires additional studies to define its role in cardiac dysfunction in conditions of protein restriction. Bers et al. [21] observed that the spontaneous release of $\mathrm{Ca}^{2+}$ from the sarcoplasmic reticulum depends mainly on the concentration of cytosolic $\mathrm{Ca}^{2+}$ and $\mathrm{Ca}^{2+}$-loading of the sarcoplasmic reticulum. Thus, the reduction of $\mathrm{Ca}^{2+}$ mobilization can act as a trigger point of spontaneous activity, conducing to increase the spontaneous release of $\mathrm{Ca}^{2+}$ during diastole. Furthermore, increased $\mathrm{Ca}^{2+}$ sparks observed in cases of cardiac dysfunction have been related to a change of the control exercised by the protein FKBP12.6 on $\mathrm{Ca}^{2+}$ channel release from the sarcoplasmic reticulum [26, 27]. Although the role of FKBP12.6 in the stabilization of the $\mathrm{Ca}^{2+}$ channel from the sarcoplasmic reticulum was recognized, little is known about the role of this regulatory protein in the pathogenesis of heart failure [26], which indicates the need for further investigations.

In the present study, was identified marked pathological reorganization of the heart parenchyma and stroma. The structural organization of the myocardium is an important regulatory factor of the cardiomyocytes biomechanics [28]. There is sufficient evidence indicating that cardiomyocytes and extracellular matrix interact in a mechanotransduction mechanism that modulates cell contractility [28-30]. Thus, although abnormalities in this mechanism may potentially be involved in the pathogenesis of cardiomyocytes contractile dysfunction in conditions of protein restriction, this relationship is still poorly understood and requires further study. 
The results indicated that severe low protein after weaning is able to induce morphological and functional changes in the heart and ventricular cardiomyocytes. The pathological changes of cardiomyocyte mechanics suggest a potential involvement of the $\beta$-adrenergic pathway that participates in the modulation of cellular contractility, which is possibly associated with changes in SERCA2a expression and disturbances in the $\mathrm{Ca}^{2+}$ intracellular kinetics. Although these findings suggest new aspects of the pathophysiology of heart disease associated with malnutrition, the involvement of $\mathrm{Ca}^{2+}$ transport proteins and the activation of signaling pathways that regulate the $\mathrm{Ca}^{2+}$ intracellular kinetics under conditions of low protein remains poorly understood and requires further study.

\section{Acknowledgements}

We thank the "Núcleo de Microscopia e Microanálise" of the Federal University of Viçosa by the assistance in scanning electron microscopy analysis, Fundação Arthur Bernardes (Funarbe) and Federal University of Ouro Preto. This study was supported by the Coordenação de Aperfeiçoamento de Pessoal de Nível Superior (CAPES) and Fundação de amparo a Pesquisa do Estado de Minas Gerais (FAPEMIG).

\section{Disclosure Statement}

The authors declare that they have no competing interests.

\section{References}

1 Cicogna AC, Padovani CR, Okoshi K, Matsubara LS, Aragon FF, Okoshi MP: The influence of temporal food restriction on the performance of isolated cardiac muscle. Nut Res 2001;21:639-648.

2 Lim K, Zimanyi MA, Black MJ: Effect of maternal low protein during pregnancy and lactation on the number of cardiomyocytes in the post proliferative weanling rat heart. Anat Record 2010;293:431-437.

-3 Okoromah CAN, Ekure EN, Lesi FEA, Okunowo WO, Tijani BO, Okeiyi JC: Prevalence, profile and predictors of malnutrition in children with congenital heart defects: a case-control observational study. Arch Dis Child 2011;96:354-360.

4 Gruber C, Nink N, Nikam S, Magdowski G, Kripp G, Voswinckel R, Mühlfeld C: Myocardial remodelling in left ventricular atrophy induced by caloric restriction. J Anat 2012;220:179-185.

-5 Penitente AR, Fernandes LG, Cardoso LM, Silva ME, Pedrosa ML, Silva AL, Haibara AS, Moraes MFD, Chianca DA Jr: Malnutrition enhances cardiovascular responses to chemoreflex activation in awake rats. Life Sci 2007;81:609-614.

6 Martins CDD, Chianca DAJr, Fernandes LG: Cardiac autonomic balance in rats submitted to low protein after weaning. Clin Exp Pharm Physiol 2011;38:89-93.

-7 Sugizaki MM, Carvalho RF, Aragon FF, Padovani CR, Okoshi K, Okoshi MP: Myocardial dysfunction induced by food restriction is related to morphological damage in normotensive middle-aged rats. J Biomed Sci 2005; 12: 641-49.

-8 Gut AL, Okoshi MP, Padovani CR, Aragon FF, Cicogna AC: Myocardial dysfunction induced by food restriction is related to calcium cycling and beta-adrenergic system changes. Nutr Res 2003;23:911-919.

-9 Penitente AR, Novaes RD, Chianca Jr DA, da Silva MF, Silva ME, Souza AM, Guatimosim S, Almeida PW, Alves MN, Felix LB, Neves CA, Natali AJ: Protein restriction after weaning modifies the calcium kinetics and induces cardiomyocyte contractile dysfunction in rats. Cells Tissues Organs 2013;198:311-317.

10 Sequetto PL, Oliveira TT, Maldonado IR, Augusto LE, Mello VJ, Pizziolo VR, Almeida MR5, Silva ME, Novaes RD: Naringin accelerates the regression of pre-neoplastic lesions and the colorectal structural reorganization in a murine model of chemical carcinogenesis. Food Chem Toxicol 2014;64:200-209. 


\section{Cellular Physiology Cell Physiol Biochem 2014;34:443-454 and Biochemistry \\ Penitente et al.: Protein Restriction and Cardiomyocytes Dysfunction}

11 Novaes RD, Penitente AR, Gonçalves RV, Talvani A, Neves CA, Maldonado IRSC, Natali AJ: Effects of Trypanosoma cruzi infection on myocardium morphology, single cardiomyocyte contractile function and exercise tolerance in rats. Int J Exp Pathol 2011;92:299-307.

12 Lauton-Santos S, Guatimosim S, Castro CH, Oliveira FA, Almeida AP, Dias-Peixoto MF, Gomes MA, Pessoa P, Pesquero JL, Pesquero JB, Bader M, Cruz JS: Kinin B1 receptor participates in the control of cardiac function in mice. Life Sci 2007;81:814-822.

-13 Carneiro-Júnior MA, Quintão-Júnior JF, Drummond LR, Lavorato VN, Drummond FR, da Cunha DN, Amadeu MA, Felix LB, de Oliveira EM, Cruz JS, Prímola-Gomes TN, Mill JG, Natali AJ: The benefits of endurance training in cardiomyocyte function in hypertensive rats are reversed within four weeks of detraining. J Mol Cell Cardiol 2013;57:119-128.

14 Coombs NJ, Gough AC, Primrose JN: Optimization of DNA and RNA extraction from archival formalin-fixed tissue. Nucleic Acids Res 1999;27:e12.

15 Rossi MA, Abreu MA, Santoro LB: Images in cardiovascular medicine. Connective tissue skeleton of the human heart: a demonstration by cell-maceration scanning electron microscope method. Circulation 1998;97:934-935.

-16 Sugizaki MM, Leopoldo AS, Okoshi MP, Bruno A, Conde SJ, Lima-Leopoldo AP: Severe food restriction induces myocardial dysfunction related to SERCA2 activity. Can J Physiol Pharmacol 2009;87:666-673.

17 Langley-Evans SC, Gardner DS, Welham SJ: Intrauterine programming of cardiovascular disease by maternal nutritional status. Nutrition 1998;14:39-47.

18 McKnight KA, Rupp H, Beamish RE, Dhalla NS: Modification of catecholamine-induced changes in heart function by food restriction in rats. Cardiovasc Drugs Ther 1996;10:239-246.

19 Li P, Hofmann PA, LI B, Malhotra A, Cheng W, Sonnenblick EH, Meggs LG, Anversa P: Myocardial infarction alters myofilament calcium sensitivity and mechanical behavior of myocytes. Am J Physiol 1997;272:360370.

20 Bers DM: Excitation-contraction coupling and cardiac contractile force; in Bers DM (ed). Dordrecht, Kluwer Academic Publishers, 2001.

21 Bers DM, Li L, Satoh H, Mccall E: Factors that control sarcoplasmic reticulum release in intact ventricular myocytes. Ann NY Acad Sci 1998;853:157-177.

22 Bers DM, Eisner DA, Valdivia HH: Sarcoplasmic reticulum $\mathrm{Ca}^{2+}$ and heart failure roles of diastolic leak and $\mathrm{Ca}^{2+}$ transport. Circ Res 2003;93:487-490.

23 Leopoldo AS, Lima-Leopoldo AP, Sugizaki MM, Nascimento AF, Campos DHS, Luvizotto RAM, Castardeli E, Alves CAB, Brum PC, Cicogna AC: Involvement of L-type calcium channel and SERCA2a in myocardial dysfunction induced by obesity. J Cell Physiol 2011;22:1-29.

24 Vizotto VA, Carvalho RF, Sugizaki MM, Lima AP, Aragon FF, Padovani CR, Castro AVB, Pai-Silva MDal, Nogueira CR, Cicogna AC: Down-regulation of the cardiac sarcoplasmic reticulum ryanodine channel in severely food-restricted rats. Braz J Med Biol Res 2007;40:27-31.

25 George $\mathrm{CH}$ : Sarcoplasmic reticulum $\mathrm{Ca}^{2+}$ leak in heart failure: mere observation or functional relevance? Cardiovasc Res 2008;77:302-314.

-26 Marx SO, Reiken S, Hisamatsu Y, Jayaraman T, Burkhoff D, Rosemblit N, Marks AR: PKA Phosphorylation dissociates FKBP12.6 from the calcium release channel (ryanodine receptor): defective regulation in failing hearts. Cell 2000;101:365-376.

27 Marks AR, Priori S, Memmi M, Kontula K, Laitinen PJ: Involvement of the cardiac ryanodine receptor/ calcium release channel in catecholaminergic polymorphic ventricular tachycardia. J Cell Physiol 2002;190:1-6.

28 Sheehy SP, Grosberg A, Parker KK: The contribution of cellular mechanotransduction to cardiomyocyte form and function. Biomech Model Mechanobiol 2012;11:1227-1239.

29 Miner EC, Miller WL: A look between the cardiomyocytes: the extracellular matrix in heart failure. Mayo Clin Proc 2006;81:71-76.

-30 Kresh JY, Chopra A: Intercellular and extracellular mechanotransduction in cardiac myocytes. Pflugers Arch 2011;462:75-87. 